\title{
Teachers Perspectives' in Curbing and Mitigating Bullying in their Work Place: A Case study
}

\author{
Eluojor A. Onnekikami, PhD (Corresponding author) \\ California State University, Los Angeles, CA, United States \\ E-mail: eonneki@calstate.edu
}

Moses Taiwo, $\mathrm{PhD}$

Grand Canyon University, Phoenix AZ

Ashraf Esmail, $\mathrm{PhD}$

Dillard University, New Orleans, LA

Agboto Vincent, PhD

Grand Canyon University, Phoenix AZ

Received: January 1, 2017 Accepted: January 28, 2017 Online published: July 19, 2017

doi:10.5296/ijhrs.v7i3.11570 URL: https://doi.org/10.5296/ijhrs.v7i3.11570

\begin{abstract}
The purpose of this qualitative case study was to examine the insights of 10 middle school teachers on how to curb incidents of bullying in their work place. In addition, a focus group consisting of four teachers honed in on their perspectives on how to intervene and prevent student-to-student incidents of bullying and cyber bullying in one middle school in Western United States. The study's research questions explored teachers' perspectives in witnessing bullying and cyber bullying in their classrooms and the strategies they utilized to identify and effectively intervene to prevent these harassing behaviors. The theoretical framework of social cognitive theory supported this exploratory qualitative case study. The theory demonstrated how students learn and derive meaning from their culture and environment. Data was collected from 10 purposely-selected participants and four purposely selected members of a focus group through personal interviews and collection of documents. Data
\end{abstract}


analysis was achieved by coding, categorizing and the development of themes or patterns. Thematic analysis revealed that teachers and parents played an imperative role in intervention and prevention of bullying and cyber bullying. Inflicting physical harm, name-calling, teasing, and cyber bullying were identified as the common types of bullying in the middle school. Given all the reported negative outcomes associated with bullying and cyber bullying, very serious attention is called for, from teachers and all stakeholders, for intervention and prevention of these harassing behaviors.

Keywords: Bullying, Cyberbullying, Intervention, Prevention, Effective policies, Golden rule

\section{Introduction}

The escalation in the number and frequency of incidents of bullying, particularly cyberbullying, as a new form of harassment nationwide and globally is well documented ( Dey Rey, Elipe, \& Ortega, 2012; Franks, Rawana \& Brownlee, 2013; Gofin \& Avitzor, 2012; Simplicio, 2013). Cyber bullying is bullying that uses contemporary technologies to victimize, harass, or bully a person or group of persons (Bhat, 2008; Hinduja \& Patchin, 2013; Nator, Padjett \& Roden, 2013). Traditional bullying is intentional aggressive behavior that often involves an imbalance of power between the perpetrator and the victims (Del Rey et al., 2012; $\mathrm{Li}, 2009)$. Bullying is also defined as unwelcome, hostile behavior among school-aged children that involves a real or perceived power inequity (Garaigordobil \& Martinez, 2013). The behavior is repeated, or has the possibility of being repeated, over time (Del Rey et al., 2012; Franks et al., 2013; Ockerman, Kramer \& Bruno, 2014). This imbalance of power sometimes involves differences in physical strength between the bully and the victim(s) (Franks et al., 2013).

The issue of bullying has become so problematic in the United States that, in response to the issue, President Obama held the first White House Conference on Bullying Prevention on March 11, 2011. During the conference, the President stated that about 33\% of middle school and high school students reported that they had been bullied during the school year and close to 3 million students reported being shoved, tripped, pushed, and spat on. President Obama also stated that bullying does not end at the end of the school day, but often follows students from their classrooms to their homes via digital technologies, in the form of cyber bullying (Cable News Network, 2011).

\subsection{Problem Statement}

It was not necessarily known what middle school teachers' perspectives were on how to intervene and prevent student-to-student incidents of bullying and cyber bullying. A need existed for the qualitative research case study that was conducted at one middle school in Western United States, because of the frequency of disruptions and fights in the classrooms associated with bullying and cyber bullying. The school predicament is supported in the literature by some researchers when they revealed that there has been an escalation in the number and frequency of incidents of bullying, particularly cyberbullying, in today's schools (Eden et al., 2013; Gofin \& Avitzor, 2012; Hinduja \& Patchin, 2011). This problem is 
exacerbated by the utilization of contemporary technologies, such as cell phones, computers, tablets, and social media, such as Facebook, Instagram, and Twitter (Dey Rey et al., 2012; Gofin \& Avitzor, 2012; Hinduja \& Patchin, 2011).

In this qualitative case study, the goal of the researchers was to assess middle school teachers' perspectives in student-to-student incidents of bullying and cyberbullying at a middle school in a small, economically disadvantaged district in Western United States as previously stated, regarding how to solve the bullying issues in the classroom. Teachers have reported to the district and their principal about the escalation in the number and frequency of incidents of bullying and cyberbullying in their classrooms. To date, the school at which the participant teachers were employed had not examined bullying or cyberbullying by utilizing a case study design to explore teachers' perspectives on how to solve the problems of these harassing behaviors. Teachers spend the greatest amount of time with their students each school day and, consequently, tend to have shared experiences that could be utilized in intervening in problematic situations and, in preventing future incidents of bullying and cyberbullying (Bradshaw, Waassdrop, O’Breenan \& Gulemetova, 2013).

\subsection{Purpose of the Study}

The purpose for this study was to seek and discern teachers' best practices in limiting disruption in their classrooms due to bullying and cyber bullying. Awareness and understanding of bullying and cyber bullying in schools could often create a safer environment for students (Hindjuja \& Patchin, 2011; Mark \& Ratiffe, 2011). Teachers' perspectives on how to solve the problems of bullying and cyber bullying incidents may contribute to understanding bullying, in general, and limit classroom disruptions by creating a learning environment that is respectful, engaging, and free from bullying ( $\mathrm{Li}, 2009$; Simplicio, 2013; Wheeler, 2011 ).

\subsection{Nature of the Study}

For this research, study participants were purposefully selected from a small school district in Western United States that has five middle schools with about 102 middle school teachers. However, only one school site that has a student population of about 800 students with 40 teachers was used. To gain an understanding and gather information during a qualitative study such as the one that was conducted, purposive selection of participants is allowed (Yin, 2014). Teacher selection was based on the following criteria:

$>$ have taught in middle school for at least three years

$>$ have experienced and dealt with student-to-student bullying in the classroom within the last school year

willingness to participate in the research study

\subsection{Research Questions}

Three key questions framed this qualitative exploratory case study. The following questions guided this research study on middle school teachers' perspective on how to solve the 
problems of bullying and cyberbullying and by conducting this study, the researchers sought to answer the following questions:

RQ1: What are middle school teachers' perspectives on how to intervene and prevent student-to-student bullying and cyberbullying incidents in one middle school?

RQ2: What are middle school teachers' perspectives on educating students about the golden rule concept as a strategy for intervention and prevention of student-to student bullying and cyberbullying?

RQ3: What are middle school teachers' perspectives on how current student-to-student anti-bullying and anti-cyber bullying policies can be made more effective?

\section{Theoretical Framework}

Bandura's Social Cognitive theory (1976), also known as the Social learning theory, was used as the theoretical foundation for this research because it supported the aforementioned qualitative case study research questions. Social learning theory is a psychosocial human behavior theory originated by Albert Bandura in the 1960s (Bandura, 1976; Crain, 2010). Bandura argued that human learning in social situations goes beyond anything most learning theorists such as Skinner had described. Bandura believed that individuals learned a great deal via imitation, and imitation often involves cognitive process. Humans tend to acquire considerable amounts of information just by observation, and mentally coding what they see.

In this study, the social learning theory was utilized as a framework to help support the teachers' perspectives on the bullies' antagonistic behaviors that negatively affect their victims in terms of physical and mental discomfort, and how to address such behaviors. The underlying belief is that children most often imitate what they have observed and learned; therefore, teachers and all stakeholders need to be aware of this tendency in order to fully address bullying and cyberbullying behaviors in the classroom. One example of how stakeholders can approach this solution using social learning theory is educating students of the golden rule principle of treating one another, as they would like to be treated; this could help in mitigating bullying in their classroom (Crain, 2010).

\subsection{Limitations}

The limitations of a case study such as this are those characteristics of methodology or design that impact or influences the interpretation of the findings of the research (Yin, 2014). The study has several limitations; this study may not be compared to other teachers' perspectives of bullying and cyber bullying because with new laws emerging almost yearly across the nation on bullying, particularly cyber bullying, tend to encroach on teachers' and administrators' responsibilities (Bradshaw et al., 2013; Hinduja \& Patchin, 2011). Additionally, the sample of $7^{\text {th }}$ and $8^{\text {th }}$ grade classroom teachers in a middle school setting in Western United Stated might not be generalized to all other classrooms across the country or world. A multi-district approach would have added more to this research. 


\subsection{Significance of the Study}

This exploratory qualitative case study is significant because its results would help to increase the body of knowledge, explain teachers' perspectives, and bring about positive social change regarding bullying and cyber bullying policies. Parents, schools, students, and the community as a whole need to understand the types of classroom disruption and other negative consequences caused by bullying and cyber bullying and how to mitigate it (Kiriakidis \& Lakes, 2013; Robinson, 2013). Armed with the right type of knowledge, teachers and schools could increase the safety and protection of their students. The recent escalations of violence in schools have highlighted just how helpless and angry students sometimes feel about bullying, cyber bullying, and the negative consequences of these harassing behaviors (CNN, 2011; Kiriakidis \& Lakes, 2013; Bryce \& Fraser, 2013).

\section{Research Design and Approach}

Within the context of qualitative methodology, the research design for this qualitative research was a case study. It provided an in-depth understanding of a real-world context such as the classroom teachers' perspectives of their students' understanding of bullying and cyber bullying and how it could be mitigated (Yin, 2014). The research design supported the collection of qualitative data via open-ended interview questions with the individual participating teachers, the focus group, and document collection such as the existing anti-bullying handbooks and the school website.

The general population for this study was middle school teachers. The sample was drawn from a target population of middle school teachers in a small school in Western United States. The small middle school comprised of 800 students, 41 classroom teachers, and 10 staff members. Ten teachers were purposefully selected and four other teachers made up the focus group that was identified within a larger group of teachers (Yin, 2014). Upon receiving an IRB approval, the school principal approval was sought and received. All the teachers were State certificated and credentialed with about $70 \%$ of them with advanced degrees in their area of study. Since a qualitative study relies on lived experiences of the participants and the meaning they bring, it is recommended that such a study should utilize a purposeful sample of the individuals who have experienced the phenomenon being studied, such as bullying and cyber bullying as previously noted (Yin, 2014).

\subsection{Data Collection and Management}

As previously indicated, the school was selected because there have been documented incidents of bullying and cyber bullying in the class rooms (Personal communication with Principal, 2014). Yin (2014) stated that there is no set "formula" to be utilized in selecting the number of participants in a qualitative study; however, it is recommended that a qualitative researcher should take into consideration the length of time the research might take to complete the study. The difficulties it will take to reach the participants, the level of resources, the difficulties that the researcher might have in transcribing the many hours of interviews, and the saturation of the data obtained. Based on the aforementioned and particularly on the level of resources available to the researchers, the sample size was 14, 10 teachers who were 
purposely selected, and an additional 4 teachers who made up the focus group. For privacy and confidentiality the 10 participants where labeled $\mathrm{C} 1$ through $\mathrm{C} 10$ and the focus group was labeled FG. The ratios were six males and four female teachers for the individual participants, with three males and one female formed the focus group.

All the teachers in the school were full time employees and credentialed. The participants were from various ethnic backgrounds. Every one of the participants that agreed to participate in the study signed the required consent form. To ascertain or ensure confidentiality, a combination of letters and numbers was used to represent each of the participants including the focus group as aforementioned. Additionally, the focus group participants were required not to discuss the group participation outside of the group; however, the researcher had no way of guaranteeing this because it was beyond the researcher's control (Yin, 2014). The principal of the school provided the necessary permission for the study that took place in the teachers' classrooms after school. The participants were also informed that all their audio taped responses will be securely stored by the use of password and locked for at least five years following the completion of the study and after that would be destroyed (Yin, 2014).

The researcher for this study utilized a purposeful sampling as noted earlier on, to select voluntary middle school classroom teacher participants who had experience and personal knowledge of dealing with students regarding bullying and cyber bullying. The researchers considered no other criteria such as race, gender, and administrative position in this purposeful sample selection procedure, thereby giving it the homogeneity criteria that were needed for a qualitative study (Yin, 2014). Furthermore, the researcher for this study utilized three sources of data for the study, including 1) the open-ended questions asked during the one-on-one, face-to-face interviews with individual participants, 2) the open-ended interview questions utilized with the focus group, and 3) document collection, such as teachers', students', and parent's handbooks, and the school website. These sources of data were appropriate for this study because they were in alignment with a qualitative case study design exploring phenomena such as bullying and cyber bullying (Yin, 2014).

\subsection{Data Analysis}

All the interviews with the individual participants and focus group were audio recorded and transcribed accurately. A folder consisted of copy of documents utilized for this research study was kept secured. Documents of bullying and cyberbullying related to this study were printed out from the school website. After the completion of the member checking process in which the study participants verified the accuracy of the transcribed information, the initial manual coding was done utilizing the recommendations by Yin (2014). The researchers started the initial stage of the hand coding process by manually going through all the interviews of the participants, by reading and re-reading each of the participant's responses identifying patterns. Words or phrases that were repeated from all other sources of data were also noted using a highlighter. The researchers manually categorized like responses for each question utilizing specific colors to identify common phrases and words. When words or phrases that appear frequently in the text were circled or highlighted using different colors. After reading all the participants' responses again, the words or phrases were reviewed, a 
short list of useful codes were identified. In the final step, the researcher reviewed the data again, to see if the identified patterns were consistent with all the sources of data and which of them could be linked together. The highlighter colors used during the coding process were green, yellow, purple, and light blue.

The aforementioned hand-coding process allowed for the identification of themes that emerged for each of the research question that the participant answered. At the end of the process, the researchers were able to show how many of the study participants experienced the same kind of experience on how they responded to the same questions. The researcher's field notes and journal were also cross-referenced with the hand-coded participants' interview data for accuracy and to help in providing a precise rich description of the key themes that were identified. The four themes that emerged from the data were Intervention and Prevention, Golden rule, Effective policies, and Professional training.

\subsection{Presentation of Findings}

Intervention and prevention emerged as one of the themes identified within each source of data collected and helped answered the first research question of the study. Each collected data source included intervention and prevention as a theme through identified patterns and language that was used by the participants and document analysis. On the question relating to the types of bullying that participants have witnessed and action taken; responses ranged from name calling, teasing, pushing, class fighting, verbal and cyberbullying and while actions taken as part of intervention and prevention ranged from putting a stop to it immediately and reporting incidents to the office if necessary.

\subsubsection{C4 Described His Experience}

Whenever I see any kind of bullying going on, I will discuss incidents with students and investigate, and if I think is a tough situation or it is really bad then, I will alert the office by calling them in advance, have security come in to pick up the students involved to the office. This is necessary so that the students do not engage in further arguments or fights on their way to the office. I will write the referral, hand it over to security, and parcel them to the office. Most often, it takes care of it. Just have to be firm with them.

\subsubsection{C9 Expressed His Perspectives by Adding}

I often deal with bullying when they occur immediately and if it is serious, I call security to take the students to the office and counselor for further investigation, so that I can teach the rest of the students. It is always the same group of students that always start stuff. I suggest teachers should try to create bullying free environment in the classroom by being very firm and post acceptable behaviors in their classroom. Do not accept any kind of disruptive behavior and do not let them get away with stuff.

Most of the participants agreed that one of the best ways to intervene in bullying incidents is by taking immediate action and not letting things escalate by putting a stop to it. One the other hand, a member of the focus group (FG) suggested that one way of preventing bullying is to bring in articles about students that have committed suicide. In addition, give it as an 
assignment, have them discuss it as group, and presented their thoughts during zero periods.

\subsubsection{Lack of Understanding}

Some participants were of the perspective that students lack understanding when it came to what bullying is about and the consequences of their behavior. This was noted on questions related to intervention and prevention that asked participants perspective on their thoughts on their students understanding of bullying or lack of it.

\subsubsection{C3 Echoed His Opinion When He Said}

In middle school students, understanding of everything is rather very limited, including bullying and cyber bullying. They tend to only understand bits and pieces of things and consequently misconceptions are rather common. If you ask them to describe what bullying and cyber bullying is all about, some of them might give you an example that is correct and some of them might not be able to do so. I do not believe that most of them have a comprehensive knowledge of what bullying and cyber bullying is about. They have no clue that bullying behavior could have severe consequences.

\subsubsection{C5 Added}

You might think that is just a simple question, but not necessarily. It is kind of difficult to know precisely whether students understand what bullying is. At this stage of their lives, they feel they are just having fun. Everything is funny to them and a joke to them. They do not take things like that seriously at all.

On the other hand, C8 is of the perspective that some of most of the students do not understand but believe that some of the good students do understand bullying.

\subsubsection{C8 Said}

Most of the students I believe do not understand the consequences of bullying; to them it is just a joke. Even if a victim is to come before the classroom and tell the perpetrators the emotional trauma that they are going through, the perpetrators will still do not understand. However, I do believe that some of the levelheaded students do understand the seriousness and consequences of bullying. They might not necessarily know the definition of bullying but they recognize that it is not an appropriate behavior.

A member of the focus group (FG) added, "I really think they know when they are being mean, they probably don't know what cyber bullying is. But they do know absolutely when they are being mean, yes they do.

Some of the participants were very concerned about the escalating rate of suicide among students as shown on TV and other news outlet associated to technology and cyber bullying. A participant stated that he is always disturbed whenever he hears the news about some students that committed suicide as result of being bullied and felt that parents of children in middle school should not allow their kids to have a face book account. Another participant felt that there is room of the use of technology in the classroom but it has to be monitored. This perspective was best summarized by $\mathrm{C} 2$ in her perspective on technology: 
I am not sure why a parent should allow a middle school student to have a face book. Tell me, what do they need a face book account for? Is it going to help them with their homework? Face book and social media as a whole is just bunch of problems. Sexting is another new word; middle school kids posting naked pictures of themselves to each other as I have heard but have not witnessed. It is crazy what is going on, with the abuse of technology. I do not allow my children to have a face book account. When they are in high school maybe.

C4 shared his experience about a traumatic event that occurred because of a student using social media by this narrative:

When they use technology such as their smart phones to bully, I do not think they fully necessarily understand its implications. For example, we have a student who posted a distorted sexually explicit image of a teacher on the face book. We are not sure how he got hold of the teacher's picture and distorted the image to make is sexually explicit. As you can imagine this spread like a wide fire around the school and disrupted the classrooms and the school building as a whole for a few days. Although the student that posted the distorted pictures was later traced and eventually expelled but this clearly a student not understanding what cyber bullying is about and the harm such behavior could bring about not only to their victims and to themselves sometimes.

The researcher noted that this one event described by $\mathrm{C} 4$ must have been very chaotic and traumatic, not only to the teachers but to the whole school during the 2013/2014 school year because the FG also alluded to it. FG stated, we sometimes have a Sherriff deputy here that deals with serious cases of cyber bullying. That is why we try to tell the kids that once you put it out there it is out there and they have not fully gotten it yet, whether it is inappropriate pictures, language, or what have you, when is out there, it is out there." The cyberbullying situation has become so unacceptable that the district had to have law enforcement in the school according to the focus group.

All the participants shared their experiences on how they handled past incidents of bullying and believed that the teacher's role is imperative for any bullying program to be successful. Most of them however acknowledged that it would take all stakeholders, working together for a successful alleviation of the problem of bullying. This view is also supported in the literature (Ockerman et.al, 2011).

\subsubsection{C1 Shared His Perspectives}

Teachers must make the effort to address all incidents of bullying immediately; I think that is fast and easy way to control it. If any bully wants to start their nonsense, make sure you let the student know that is not an acceptable behavior. Students often want to see what they can get away with. Students should report any acts of bullying to their teachers and office immediately. Some of the bullying behavior might even start in the bus on their way to school, students should report the bully immediately to the office upon arrival to school.

C2 agrees with $\mathrm{C} 1$ when she added, "My method of intervention with bullying incidents is to confront the students that are involved, hold meetings with all concerns and the serious incidents I often report to the office for further assistance. My recommendations to teachers 
are that we must continue to apply good basic classroom management by teaming up with the administration when incidents of bullying occur." These participants are of the perspective that simple things like, telling students that they are in school to learn, modeling expected behavior helps in curbing unacceptable behaviors. Additionally, sending students to other classrooms when they are misbehaving can also help. When students are no longer with their friends to fuel their stupid behavior they tend to behave. They also indicated that teachers should not just send a student to another classroom; they should make sure they are given assignments to do while in the new classroom otherwise; they could become a problem there.

C10 had a slightly different approach on the role teachers can play in alleviating the incident of this harassing behavior when he stated:

To prevent bullying, I think if you can bring out real cases, show them, and have people share their experiences and how it affected them that might help. Sometimes teachers should share stories of how they handle bullying during their middle school days. That could help. When you have celebrities talk about how they were bullied, what they went through and how they survive it these things can also have an impact.

As previously noted, C10 perspective differ in the way he thought bullying could be prevented. Like the FG, C10 believed that teachers should talk about real life cases of bullying and have the students share their views in writing. Additionally, he believed that teachers should share their bullying stories while in middle school and how they handled it. If all these are followed, it might help in the reduction of bullying and cyber-bullying incidents the participants stressed. This teacher's view, in other words, is all about classroom management. A successful classroom management is about creating an atmosphere where students can feel safe and learn. Students tend to respect a teacher whose classroom management skills are good and fair. Students in such classrooms tend to have less disruptive behavior (Allen, 2010).

Most of the participants and the literature review agreed that the role of parents is paramount if bullying and cyberbullying is to be reduced and eliminated (Robison, 2013). C6 is of the opinion that parents should always find out from their children as to what is going on in their lives. He believes that parents must get involved with their children's teachers to find out how they are doing in the classroom.

\subsubsection{C6 Shared His Perspective}

Parents have a big role to play when it comes to trying to stop bullying and cyber bullying. Parents should always ask themselves does my child really need a cell phone. I don't think kids need a face book account, twitter, do they really needs that in middle school or high school? The answer is no. They do not need that stuff, they really don't. I think also one of the best ways to deal with bullying is through their parents. Parent asking kids what is going on, what is happening in their child's life. Go to church, the bible that is a huge thing, and all families members should be involved in. Parents should train kids the traditional way. Lack of discipline at home and low self-esteem could be attributed to a big source of bullying. 


\subsubsection{C8 Expressed His Opinion When He Said}

Lack of discipline from home and low self-esteem could be attributed to a big source of bullying. When parents refuses to discipline their children, when they misbehave that often can be a contributory factor. Parents should pay attention to what their kids are doing both at home at school. Call the school sometimes to find out what their kids are up to.

\subsubsection{C9 Added His View on the Role Parent Can Play in Helping Curb Bullying by Stating}

Parents and guardians should encourage their children to let them in, in whatever is going on in their lives. Students often do not want to say anything to their parents for the fear of being considered weak by their peers, but if a parent presses, some kids might open up.

\subsubsection{One of the Members of the Focus Group (FG) Added}

Sometimes bullying has something to do with the home life. As a kid my sisters bullied me at home so at school I felt no different when I was being bullied at school. So most of the victims of bullying know when they are being victimized. Many of these kids have no boundaries at home either and how can they understand boundaries at school? Therefore, you understand why we have to set boundaries here. I understand the fact that the kids will wander until they find the fence but that does not mean they should not have boundaries. Parents need to teach their kids about boundaries.

The result further indicated that $100 \%(\mathrm{n}=10)$ of the teachers have witnessed some sort of bullying and have taken various actions to combat it when it occurs. As alluded to earlier $\mathrm{C} 1$, C2, C7, C9 and FG have all witnessed name calling, teasing, pushing and physical bullying. While, only C4, C9 and C10 stated that they have witnessed cyber bullying. C2 took action by reporting bullying incidents to the office when they occur, but $\mathrm{C} 2$, like one of the members of the Focus group as previously stated said they often confronted the students involved by holding meetings with them and resolving it, and only in serious cases do they send them to the office. Most of the participants did mention that when the situation is deem very serious they get the office and security involved and that seems to resolve it faster. Table 14 shows summary of the participants' responses on the types of bullying they have witnessed and the actions taken to intervene.

\section{Golden Rule}

Golden rule as a concept emerged as the second major theme during the thematic analysis and helped answered the second research question of the study. All the participants gave their perspectives on related questions of the golden rule concept. One of the questions was if educating their students about treating each other, as they will like to be treated would be effective in averting bullying and cyber bullying. The review of the transcripts revealed that some of the teachers were already using the concept to avert bullying and have been successful in using it. The only issue or point of disagreement came with the delivery methodology of the concept. Most, however agreed that announcements of the golden rule could be utilized as one method in prevention of bullying.

Clbelives that the golden rule could be helpful in curbing bullying, by sharing this 
perspective:

I think it should be incorporated as part of the curriculum. As teachers, we should teach them what it means to treat each other, as they will like to be treated. It should be taught as part of the school curriculum, just as we teach any of the core classes like Math and English. Maybe we should include it as part of social studies or something.

C5 shared her view on the golden rule by adding:

Personally, I am a faith-based teacher, I take God to my classroom but I do not talk about God in my classroom. However, I talk to my students about when you hurt somebody, it does not go away, it stays in you. I share with my kids about how I got called different names when I was in middle school because I was chubby. I started being bullied when I was 8 years and remember it until today; I tried to remind them that it does not go away. They listen and some seems to be responsive to that. I applied the golden rule in my classroom and I believed it helps my students. A member of the focus group (FG) also, "I had a class that has a bit of bullying going on, my first period class. Kind of the golden rule thing, I pulled it out, and it was very effective, I did see a transcription from my kids. I often stop the English class and talk to the students about joining the human race and start treating each other as they will like to be treated and I saw a lot of progress with that.

Most of the participants' believed that if the golden rule concept if taught to students could help in the reduction of bullying. For example, $\mathrm{C} 1$ is of the opinion that, it should be made part of the curriculum. He felt that it should be taught as any of the core classes such as Math and English. C3 stated that he has used the concept before in addressing bullying issues in the classroom and it worked effectively. A participant however warned that some students might try to turn the golden rule concept around by interpreting the opposite of the true meaning of it. They might say things like "well such and such a person was mean to me so I will be mean to them." He believed the best way to avoid such situation is for teachers to clearly state to the students the intended meaning of the concept of everyone treat each other positively as they would like to be treated.

In responding to the golden rule concept and related questions, $70 \%$ of the participants $(n=7)$, believed that educating students about the need to treat each other as they would like to be treated would help in reducing bullying. For example, C3, as previously noted, is an advocate of the golden rule idea because he has used it in his classroom in teaching his students to treat one another as they would like to be treated and it worked like "magic." However, some of the participants believed that a holistic approach that goes beyond the golden rule concept should be utilized in curbing bullying. C2, felt that a holistic approach that incudes other methods is needed. His view was supported by C9 when she stated, "teachers should create a bullying free environment in the classroom and post acceptable behaviors." One of researcher noted this comment about posting "acceptable behaviors" in the classroom because none of the classroom in the research site had any such posting.

Most of the participants believed that the golden rule should be announced but opinions differ on how many times a week and some questioned its effectiveness in reducing bullying and 
cyber bullying. Few of the participants believed that, announcing it daily could lead to students turning it out or as a focus group member put it "Charlie Brown syndrome." In other words, the students hear the announcements or words associated with it but do not listen to the content. It is tuned out. However, C7 believed that announcing the golden rule daily would work when she stated that, "I do believe that daily announcements of the golden rule will help. If not daily, two to three times a week will help but also following up with assignments or discussion in class as well." C7 perspectives about announcing the golden rule daily differ from that FG view about being tuned out. To address this FG concern, C7 is of the opinion that if not done daily it should at least be done two to three times a week and it should be followed up with a brief discussion in the class. She however, stressed that announcing it daily is good because it will be keep the concept in their cognition. She believes if one wants to be good at anything one has to practice it she argued.

C8 had a slightly different opinion when he stated "Announcing treating others as they will like to be treated, yes I do believe that it will help if accompanied by a short video as we were doing before all the cuts." However as one participant acknowledged, there could be a problem with this approach, in that it might be costly to have a video program done on consistent basis due to budgetary reasons.

The focus group (FG) opposed announcing the golden rule daily when three of the group stated, "Announcing it daily maybe, it might make it more cognizant for the students. One former principal used to do that but after many times of doing that it goes through one ear and goes out of the other." The researcher noted that FG opposition to announcing the golden rule daily is because of FG perspective that the "Pledge of allegiance" is already not being taken seriously in the school. The students say it but does not mean much to them they alleged. Based on that premise they believed if the golden rule is announced daily, it might also be disregarded by the student. However, they all later agreed with the only member is the group that supports some sort of announcements when she said "Announcing it daily is better than doing nothing." .

Some of the participants believed that education and modeling of the golden rule concept might help in the reduction of bullying. A participant talked about how he used the golden rule concept in a video format to teach students in the past, and how successful it was before the program was cut due to budgetary reasons as pointed out earlier on. This participant was concerned about legal implications. The researcher noted this view because the golden rule concept is a Christian doctrine and since the community comes from different religion background, some parents might not necessarily agree with it.

C8 gave a detailed account of how the golden rule was used in the past and how during the period, there was a remarkable decrease in bullying in the school. The program first got started when some group of students came from a different school district and modeled bullying as a drama for the whole school, according to this participant. The response from the students was so great, that the then principal appointed him to start creating video skids with the students as actors and was aired during zero periods of that school year..

C8 concurred with $\mathrm{C} 10$, that educating and modeling of the expected behavior and 
unacceptable behavior might go a long way in helping with the reduction of bullying in the school. C10 and some of the participants talked about a show that was brought to the school in the 2013 school year, which modeled acceptable and unacceptable behavior on bullying and was very successful as previously pointed out. During the weeks after the show, they felt that the bullying atmosphere was subdued in the school. However, since there was no follow through after the show to remind the students about what is acceptable and not acceptable, the bullies seem to have gone back to bullying again. These participants believed that if such aforementioned program is done on continuous basis as part of a holistic approach, it could help in the reduction of bullying.

\subsection{Effective Policies}

On the line of questions relating to the third research question of what middle school teachers' perspectives are on how current student-to-student anti-bullying policies could be made more effective. The review of the transcript indicated effective policies as one of the themes while consequences and consistency of implementing the policies were related phrases, and helped answered the third research question of the study. Some of the participants believed that there is not a clear set of policies and consequences regarding bullying and cyber bullying within the school because of a lack of leadership from the district. Some participants are of the opinion that the district does not have any existing policy on bullying. The question on how to make the existing policies more effective brought an interesting response from at least one of the participants.

C1 expressed his perspective when he indicated, "I don't believe we have an existing policy on bullying in this school, so it is impossible to suggest how it can be improved when we don't have one." This response indicated that this participant, like most of the participants, appears not to be aware of the bullying policies as published on the school website. On the other hand, $\mathrm{C} 2$ appears to differ by stating:

There must be some sort of policy on bullying somewhere but I have not paid attention to it, to be honest with you. I tried to solve it when it occurs in my classroom. Come to think of it, I glanced through the handbook in the beginning of the school year; I think it said something about it. However, all the participants agreed that for any bullying policy or policies to be effective the consequences must be spelt out and consistently applied without favoritism to students and their parents.

About $80 \%$ of the participants $(n=8)$ were not aware of any existing bullying policies; however, they gave suggestions how it could be made effective one when one exists. For example, C1 said, "When we have set of policies, teachers and parents need to be educated on what they are." C2 is of the opinion that a good bullying policy should be based on teachers and all stakeholders' inputs. However, it is noteworthy that at least two members of the individual participants know about the school website that detailed the district policy on bullying. When asked how they found out about it C7 indicated that he was just surfing the school website and they ran into it.

Bullying is a real problem in this school. To form an effective policy a research study such as 
this is definitely a good start. Gathering information or perspectives of teachers would go a long way in coming up with a good policy. She believed that seeking the perspectives of teachers on how to mitigate bullying is a step in the right direction.

The participants were of the opinion that for a policy or policies on bullying to be effective, the consequences must be clearly stated and the district should do a better job in making sure the teachers and students are notified of such policies. They were of the opinion that it was not the case presently in the school where the study took place. As previously noted, C3, like $\mathrm{C} 10$, believed that for the school to have success in reducing bullying, teachers' views must be a big part of it and there should be ongoing analysis as to the effectiveness of the program. He felt, that the current research study that was being conducted seeking their perspectives was a step in the right directio

C4 is of this perspective that, "To have an effective policy, I think there should be clear or well written consequences that teachers can impose on student when the bullying behavior occurs." This participant is of the perspective that bullying policy should have lesser consequences for minor bullying incidents such as name calling or teasing and greater consequences for chronic or very serious bullying and cyber bullying. The participant also stated that for a policy to be effective it should also define bullying and state when teachers and staff could intervene. This participant strongly believed that there should be different categories of punishment depending the severity of the bullying episode as noted by the researcher. This might not be effective because who will decide on the categories and parents could complain and even sue the district if they feel that the bullying episode was not severe in their perspectives.

On the other hand, C7 stated, "There are a couple of things the district can do to help the teachers, maybe when we do have our staff meetings, there should be a portion during that time that should be used to discuss bullying." This view is important because it was noted that the teachers have staff meetings once a week and as this participant suggested portion of the time should be used to train teachers how to deal with bullying. She also suggested that the district should send emails, to keep teachers updated and create a teachers' newsletter to inform or remind them what the policies are specially when there is an update since there might be new laws on bullying. She commended the district on the school website where students can report cyber bullying, and felt is a step in the right direction but most of the teachers and student are not aware of the site. She said "The district needs to find a way to let everyone know more about the website. I don't even have a postal in my classroom about bullying that is to show you how far back we are." In support to one of C7's aforementioned recommendations, the researcher as previously noted that most of the participants agreed that during the staff meeting a portion of the time should be allocated in discussing how to handle bullying cases but as it is, that is not even been talked about.

According to the focus group (FG), "The problem is that the district might come up with something but lack follow through or reinforcement to go along with it." FG believed that there is no consistency of implementing bullying policies. They believed that there is a need for the district to be consistent in implementing any bullying policies. They felt that one of 
the problems with the district is that they lack the will to follow through in policies by lack of commutations. For any bullying policies to work there should be a strong communication between the district and the school most of the participants agreed.

\subsection{Professional Training}

Professional training for the teachers emerged as one of the themes and helped addressed the last research question of the study. Some of the participants felt that they were using the experiences they have obtained as parents and adults to deal with bullying and cyber bullying. They felt that the district does not provide them with the needed training on how to deal with bullying, especially with the ongoing phenomenon of cyber bullying. For example, C3 stated "For bullying polices to be effective, teachers must buy into it and be professionally trained."

FG added the following perspectives on professional training, "I think the district should make a social interaction elective with citizenship and educate teachers, so that they in turn can educate the kids on what social interaction is about." In other words, the focus group members are suggesting that educators should have greater hand in educating the students about bullying. Additionally, they stated that the district should provide additional education to all students by arranging a field trip to the museum of tolerance. This idea by the FG as some of them agreed could be too costly since school district often run on tight budgets.

All the participants in this study stated in one form or another that the district has not provided them with any kind of ongoing professional training on bullying and cyber bullying that is needed. Most of the participants appeared to be at a loss as to what the policies were on bullying. The researcher noted that most of the participants were not aware of the detailed policies on bullying as stated on the school website. Some felt they are consistently trying to teach and have no time to view the school website. They all believed that for any of the policy or recommendations they gave to work, the district must provide professional training. .

\section{Discussion of Findings}

The first research question of this study was analyzed using codes that were identified from sources such as the data transcriptions and documents. From the one-on-one and focus group interviews, the participating teachers were able to discuss, shared their bullying and cyberbullying experiences of their students and how they were able handle the situations when the incidents occurred. The researchers discovered that the participating teachers discussed in detail their perspectives about their students' limited knowledge of bullying and its negative consequences, and how they believed it could be solved by educating them.

As previously noted, one of the major themes that emerged on this question was intervention and prevention, with phrases such as lack of understanding, technology, teacher's role, and parents' role associated with it. According to most of the participants, majority of the students, do not consider their behavior to be bullying, they often felt that they are just joking or having fun at the expense of the victims. However, one of the participants, in response to a related question on intervention and prevention, felt that most of the bullies do understand when they are being mean and know exactly what they are doing. This perspective is 
supported in the literature by some researchers when they alluded that the intention of the bullies is to harm, threaten, humiliate and create a sense of helplessness and fear to their victims (Austin, Reynolds, \& Barnes, 2012; Carter, Jernica, \& Wilson, 2015; Fanti \& Georgiou, 2013).

Most of the participants believed that most of the students do not fully understand the concept of neither bullying nor cyber bullying, nor do they understand the negative implications of their behavior. In middle school, most students at this stage of their lives are often trying to and find themselves and most things such as bullying seems funny some of the participants stated. They believed that most of the students might not be capable of defining the concept of bullying and cyber bullying if they were asked to do so. The literature supports this teacher's perspective. For example, some researchers are of the opinion that the concept of cyber bullying was not in existence just a decade ago but has become a contemporary problem among today's adolescents and the absence of a universal definition of the concept is often due to the lack of conceptual clarity (Bhat, 2008; Bradshaw et al., 2013; Notar et al., 2013). The participants, as supported by the aforementioned researchers, believed that students need to be educated clearly on what bullying and cyber bullying is about. To achieve this goal, the participants believed that any comprehensive education on bullying must have a clear definition of the concepts and the technological tools that are utilized by the perpetrators.

The participants also believed that students do not understand the consequences of their bullying behavior, such as low academic achievements and absenteeism of the victims or even suicide. The view of low academic achievement of the victims by the participants and absenteeism is supported in the Kiriakidis \& Lakes, (2013). The researchers indicated that students who are victims of bullying and cyber bullying are often afraid to attend school (Allen, 2010; Ockerman et al., 2014). They are often overwhelmed with concerns of the possibility of triggering another episode of the harassing behavior, particularly if the suspected perpetrator is in the same classroom. That tends to cloud the victim's ability to focus during class or studies at home. Consequently, trying to maintain academic success tends to prompt additional stress for the emotionally distraught victim that teachers and parents might not necessarily foresee. Therefore it is important for classroom teachers and parents to educate students about the repercussions of bullying and cyber bullying ( $\mathrm{Li}$, et al., 2012; NCES, 2011; Simplico, 2013).

The participants of the study believed that most of the students who bully or cyber bully are fully aware of the tools that are used to bully their victims. The tools mostly used in cyber bullying according to the participants and supported in the literature include but not limited to smart phones, home computers, and lap tops. The influxes of today's technology tend to make perpetrators feel that they are invincible because of the difficulty associated in tracing their nefarious activities (Albdour \& Krouse, 2014; Bradshaw et al., 2013; Hinduja \& Patchin, 2011; Ybarra \& Mitchell, 2004). The perpetrators of cyber bullying often utilized Facebook, chat rooms, blogs, and texting to bully their victims and this view is supported in the literature by Notar et al., (2013). The participants also believed that most of the students are not being supervised at home and often are allowed to do whatever pleases them on their 
computers. Some suggested that parents get some kind of software with lock that will prohibit students from going to some websites that parents do not authorize their children to go to. For example, C6 stated, "Parents should look into software that will block authorized websites just like we have in this school." This view was also supported in the literature (Li et al., 2012; Robinson, 2013; Whitson, 2015).

Most of the participants agreed that it is important for teachers to intervene with bullying immediately when it occurs and the use of basic classroom management is recommended. They all agreed that minor bullying issues should be handled by talking to the students involved and serious cases should be sent to the office and the school counselor. Ockerman et al. (2014) support this view in the literature, when the researchers alluded that school counselors are in the unique position to offer students social skills and character education that would emphasize positive peer conflict resolution.

Some of the participants believed that teachers could play a bigger role by educating the students on an ongoing basis about bullying and its consequences, preferably during zero periods. They believe it could go a long way in intervention and prevention. Some participants mentioned that once or twice a year, a program on bullying and cyber bullying was done, during which period student awareness increased. But shortly after that, the perpetrators went back to their old ways because there was no follow through to back up the learned acceptable behavior after the program took place. So lack of training of students and staff on bullying and cyber bullying tends to be the problem.

Research also indicates that many parents often feel ill-equipped to respond to cyber bullying. In a 2009 survey, the results indicated that $84 \%$ of parents did not know how to respond to cyber bullying because they felt that they did not grow up in the online era and consequently are unfamiliar with contemporary technologies. They felt that they have been born a generation too late and can not necessarily relate to online etiquette. Even if a parent is internet savvy, they are often astounded by how easily their young children and adolescents can navigate and adapt to new advanced and ever changing technology (Robinson, 2013).

There is a general sense within the literature that parents and adolescents think differently when it comes to the cyber world. For most adolescents, the cyber world or online environments are seamless in providing a holistic arena of learning, communications, socialization, play and research (Olweus, 2010; Perlus et al., 2014; Shariff, 2008). Most adolescents do not necessarily see any difference between online and traditional bullying. For example, in some studies, participants described cyber bullying simply as bullying using the Internet (Del Rey et al., 2012; Gofin \& Avitzor, 2012). Some other studies further supports the idea that adolescents who perpetrate cyber bullying tend to also engage in traditional bullying, and many young individuals who have experienced cyber bullying have also experienced traditional bullying (Olweus, 2010; Shariff, 2008; Whelan, 2011). The participants believed that parents should be monitoring their children' activities online, question, and stop any activities they feel are inappropriate as indicated earlier on.

The participants suggested that parents be educated via parent/ teachers meetings on a regular basis on bullying and cyber bullying. The participants stated that even though everyone on 
the campus knows that bullying concerns are problematic in the campus, it is not necessarily being discussed at any time during the weekly meeting in the principal, teacher and staff meetings. The participants believed that placing the bullying and cyber bullying topic on the agenda during Tuesdays' meeting and educating the students on the topic during zero period every school day as previously discussed, could go a long way in ameliorating the situation and mitigate bullying and cyber bullying in their classrooms.

As noted earlier on, some participants were of the perspective that classroom management is the key in intervening and preventing bullying. The key they believed is that teachers must always have a good teaching daily lesson plan and when students are kept busy taking notes and learning, they tend to have less time on their hands to be bullying. This classroom management view is supported by Allen (2010), when she alluded that one of the major contributing factor to classroom chaos and interruption to learning to the classroom learning atmosphere tends to occur when a teacher is ill-prepared to teach due to lack of lesson plans for the day. Teachers with good lesson plans tend to manage their classroom better than those that do not she implied (Allen, 2010).

The participating teachers also recommended a holistic approach in mitigating bullying, which is also supported by various researchers (Bradshaw et al, 2013; Ockerman et al., 2014; Whitson, 2015). The researchers suggested that schools should use a wide holistic approach that offers universal interventions that is based on respect, caring, positive discipline that supports clear acceptable behavioral expectations and consequences. All such approach must also entail parental involvement. The goal is to create an environment or culture in which all adults involved in a student life could stop bullying incidents immediately they occur be it at school or at home (Allen, 2010; Bryce \& Fraser, 2013; Robinson, 2013).

The Golden rule emerged as the second major theme during the thematic analysis with announcements, education and modeling as related phrases. All the participants gave their perspectives about the concept of "golden rule" which is the idea of educating their students about treating each other as they will like to be treated and it would be effective in averting bullying and cyber bullying. The review of the transcripts also revealed that some of the teachers were already using the golden rule to avert bullying and have been successful using it. The only issue or point of disagreement came with the delivery of the concept. Most, as previously discussed, agreed that announcements of the golden rule could be utilized as one method in prevention of bullying but have the potential drawback of being tuned out by the students.

However, research suggests that frequent repetitions are indispensable in order to make possible the retention of a given content such as announcing the golden rule concept of treating each order as one will like to be treated. Prepared announcements, discourse and vocabularies of any length cannot be learned by a single repetition even with the greatest concentration of attention on the part of an individual or students of very great ability. Simply put, repetitions of announcing the golden rule of treating each other as they would like treated as frequently as feasible could help in the reduction of bullying. Most of the individual participants believed that educating the students on the "golden rule" concept of treating each 
other, as they would like to be treated would be helpful. By announcing it daily as part of the on-going daily announcements in the school could help in the reduction of the incidents of bullying and cyber bullying, provided it has the full support of the school administration. Robinson (2013) also supports this teacher's golden rule perspective in the literature when he alluded that the most imperative rule in dealing with bullies is to teach them about treating each other as one would be liked to be treated. They believed that this tenant of behavior flows from all other rules. However, as previously noted, most of the members of the focus group believed that announcing the "gold rule" daily as part of the scheduled daily announcements' could be problematic because they believed that most of the students would not pay attention to it because of information overload and would eventually be tuned it out. However, all the members of the focus group did agree that it is better to do announcements than doing nothing regarding mitigating bullying.

Some of the participants believed that the school and district leadership support would be paramount if any program such as announcing the golden rule concept daily and putting it in some sort of print, like the school monthly newsletter to parents and guardians. The participants stressed that creating such a culture of affection in the school building and class rooms could encourage a positive relationship on a day to day basis. This view is also supported in the literature by Austin et al., (2012), when they recommended that one of the first steps in preventing bullying is creating a culture of affection by establishing an effective school policy that is acceptable not only to teachers but to school counselors, principals, administrators and other stakeholders such as parents and guardians. Such policy should be fair to all students and should be administered by the school consistently. The focus should be on the positive behaviors of the students (Allen, 2010; Keith \& Martin, 2005; Kowalski et al., 2014). .

Most of the participants believed that the most common type of bullying that goes on within their watch is often name calling, teasing, taunting and mockery of the victims as previously discussed. This view is supported in the literature by some researchers, when they alluded that verbal bullying is made up of taunting, teasing, or mocking the victims in a face-to- face manner. The behaviors that can be perceived as verbal bullying include and are not limited to: telling hurtful jokes about individual, rude remarks, calling individuals hurtful names, and threatening them. It can also take the form of direct or indirect bullying. The bully can do the bullying by confronting their victims directly or indirectly behind the victim's back. The intent of verbal bullying often is to humiliate and intimidate their victim in front of others or provide some type of humor amongst a group at the expense of the victim's reputation (Bhat, 2008; Fanti et al., 2013; Hinduja \& Patchin, 2013; Simplico, 2013).

The participants further believed that if students are to model the unacceptable behavior of name calling, teasing, and rude remarks in a role play, recorded and shown during zero periods, the perpetrators of bullying might get the message because they will learn that is not acceptable when they are the ones be called names and teased. A participant talked about how modeling the acceptable behavior by treating each other as one would like to be treated was the norm during a drama and theater class he taught and the program was cut due to budgetary reasons as previously stated. However, some researchers noted that, modeling of 
acceptable behaviors should actually begin with the classroom teachers. Teachers should endeavor to establish a positive, friendly and trusting relationship with each one of their students. This is particularly imperative with aggressive students that are acting out, who may be exhibiting these behaviors as a result of negative experiences they had experienced with some adults in their life (Bandura, 1976; Crain, 2010;). The researchers believed, that it is often easier for students to accept constructive criticism, if they feel appreciated and respected. Additionally, students tend not to respect a teacher or follow the school bullying rules if they feel the teacher is unfair, sarcastic, or abusive. In summation, all stakeholders must be treated with respect and their views taken into consideration when a holistic approach on bullying is being considered (Allen, 2010; Bradshaw, 2015; Kowalski et al., 2014; Olweus, 2010; Robinson, 2013).

Most of the participants were of the opinion that there was little or no student anti-bullying and anti-cyber bullying policies in existence. Some were not aware or have not heard about the website that was set up by the district to report incidents of bullying and cyber bullying until it was brought to their attention by the researcher. The major theme on this question was effective policies, while consistency and consequences were related phrases. However, the legal notice for parents and guardians document that the researcher printed out from the website was very detailed about the district policy on bullying and cyberbullying. The document stated that the district and its governing body recognize the harmful effects of bullying and cyberbullying on student learning. A page titled "bullying prevention" from the school website (2014) also stated that one of the goals of all the schools in the district is to provide a safe learning environment that will protect all students from emotional and physical harm. The document also stated that it is the responsibility of all the school staff to make student safety a high priority and bullying of any student in the district should not be tolerated.

The strategies for bullying prevention according to the document are expected to be developed with involvement of all key stakeholders in accordance with the board policy, state laws, and the district regulatory body in the development of comprehensive anti-bullying plans. The document stated that students in the district should be informed, through all appropriate means, including student handbooks, of the district rules or polices as related to bullying and the consequences of those that engages in such negative behavior. The students in the district were expected to be provided with anti-bullying instructions in a classroom setting that will promote conflict resolution skills, assertiveness skills, respect for cultural and individual difference, self-esteem development and an acceptable or proper online behavior. The school district was anticipated to provide teachers and other school staff professional development on how to detect early warning signs of intimidating behaviors and effective intervention and preventions strategies as also supported by some researchers (Bhat, 2008; Eden et al., 2013; Gofin \& Avitzor, 2012; Kowalski et al., 2014).

The document also indicated that all students in the district should be encouraged to notify their teachers or any school staff when they are being bullied or suspect that their fellow students are being bullied. The aforementioned page on the website also indicated that a designee or the superintendent should develop means in which students could report incidents 
anonymously and confidentially. The document stated that any school staff that witnesses any kind of bullying should immediately stop the incident when the staff feels it safe to do so.

When the situation involves cyber bullying, individuals or students with information about such an incident or activity would be encouraged to print and save any digital or electronic messages that is sent to them that the victim feels constitute cyberbullying and to immediately notify their teacher, principal or other staff members so that such allegations would be investigated. If the perpetrator is utilizing a social media such as Facebook that has terms of use that prohibit posting of messages considered harmful, the Superintendent was expected to file a complaint with such social media so that the harmful materials might be taken down.

The analysis of the document also revealed that a student or group of students that engages in bullying on school premises or from their homes in a manner that causes a rather substantial disruption of school activities or attendance were expected be subjected to discipline. The discipline could include suspension and depending on the severity, could lead to expulsion, in accordance with the district regulations and policies. Most of the participants stated that they have not heard or read the aforementioned document or policies.

Most of the participants, in responding on how to make an existing policy more effective, believed that all bullying policies must state clearly, what would be the consequences. any student that is caught bullying. Equally important was that all disciplinary actions applied for any student caught bullying must be consistent. There should be no favors done for any student or for their parents. This teacher's view is supported in the literature, when Robinson (2013) alluded that schools whose administrators hold school assemblies to educate their students about acceptable digital citizenship and clearly stated consequences tend to see positive outcomes about the empowerment of teachers in the school in preventing bullying..

Furthermore, some researchers noted that holistic anti-bullying programs that include some type of family components tend to be most effective at mitigating bullying (Del Rey et al., 2012; Robinson, 2013). Families often play an important role by providing emotional support that will promote or disclose bullying incidents that will otherwise be hidden by their children (Bradshaw, 2014). One of the best ways of getting their children to talk, as some of the participants also suggested is to do it during dinner time; to find out how their children's day went and it should be done at least four times a week (Robinson, 2013). During such dinnertime, parents that discovered that their children were victims or perpetrators of bullying can then come up with solutions on how to deal and communicate their concerns of bullying and cyberbullying to the school administration (Robinson, 2013; Whitson, 2012).

Given the complex nature of bullying and cyber bullying, it is recommended that schools in general implement integrated components, which will target different aspects of bullying behavior and create an atmosphere that supports anti-bullying efforts (Bhat, 2008; Bradshaw, 2014; Whitson, 2015). This is in sharp contrast to the typical single-session school assembly on bullying, which some of the participants alluded to, which increased bullying awareness but were not followed through. Research highlights the importance of providing a class time after a major assembly to discuss bullying and cyber bullying (Austin et al., 2012; Eden et al., 
2013). Utilizing the lessons learned from such an assembly to foster emotional and social skills, effective communications and appropriate strategies for responding to bullying incidents is essential (Austin et al., 2013). Programs that have the suggested broader focus that addresses social and emotional skills and interpersonal conflict resolution skills could be very helpful to the students (Bhat, 2008; Bradshaw et al, 2015; Whitson 2015). All the aforementioned should be taken into consideration by the school district in their anti-bullying efforts. Additionally, the district has to communicate the policies to all teachers, parents and students not just posting it on the website, hoping that the aforementioned stakeholders will surf into it.

\section{Conclusion}

A school wide effort should be made by all stakeholders to implement a comprehensive bullying prevention and intervention program. An ongoing bullying and cyber-bullying program would enable the students to understand and recognize that the school is committed to protecting them from those that bully them. After establishing such awareness, the school administration should develop a firm set of policies that include a precise or clear definition of bullying and cyber bullying. The schools should also outline clearly the procedures for reporting incidents of bullying and cyber bullying (Bhat, 2008; Bradshaw, 2015; Gofin \& Avitzor, 2012). Instructional methodologies such as modeling the expected behaviors using video skits and classroom activities should be utilized to increase students' understanding and awareness of behaviors that the school classifies as bullying. This can effectively enable teachers to enforce classroom and school polices as related to bullying. In addition, awareness could provide the students with the opportunity to expand their horizon of accepted behaviors and expand their social circles (Bradshaw, 2015; Bradshaw et al,, 2013; Olweus, 2010; Shariff, 2008).

Within the set bullying policies, a list of ramifications when bullying occurs should be clearly stated and all school staff must adhere to following through by enforcing the policies consistently and fairly. For example, the principal of a school could talk to all the students, clarifying the behaviors or actions that would be considered bullying on an ongoing basis; discussing what would be acceptable response to bullying and the expected consequences if such behavior continues. As the participating teachers mentioned, bullying polices will not be effective if teachers and other staff members are unfamiliar with the district anti-bullying policies, and what their responsibilities are in enforcing them. Since teachers, as this study has indicated and supported in the literature, spent the greatest amount of time with their students during the day, it is important that teachers are trained monthly during the school year on bullying (Allen, 2010; Austin et al., 2012; Kowalski et al, 2014; Whitson, 2015).

By increasing their knowledge, teachers could recognize when to intervene in cases of bullying and cyber bullying. In addition, teachers should be encouraged to hold a weekly ongoing discussion with their students about the school anti-bullying polices and answer any questions the students might have. This could be done during the zero period, which is the first 20 minutes of the day when students are expected do any uncompleted assignments.

Classroom teachers should collaborate with counselors to develop classroom guidance and 
skills that students need when they experience bullying and cyber bullying. All school personnel must clearly communicate to victims of bullying and cyber bullying that they are not at fault when incidents occur. Such interventions and encouragement could help with victims' self-esteem. In addition, such intervention could help the victim identify personal accomplishments' and strengths, thereby instilling feelings of confidence and pride and this will enable them to shield themselves from future occurrences. All students should be trained to be assertive (Bradshaw, 2015; Garaigordobil et al., 2013).

Students should practice assertiveness through role playing or modeling activities, in developing confidence in their abilities in responding assertively in a variety of bullying situations. Students should also be trained to improve their social skills. This will help them develop good relationships with their peers and friends, which could decrease their chances of being victimized (Bradshaw, 2015; Whitson, 2015). Additionally, schools should educate their students on the need to treat each other as they would like to be treated. This is important to all students but particularly to the perpetrators of bullying. The immediate step that could be taken to accomplish the concept of golden rule is by announcing it in different formats daily during the daily scheduled announcements. A suggested example of such announcement could be: "This school is a 100\% "Golden Rule School"-that means-we treat each other as we would like to be treated. Bullying and cyber bullying are completely unacceptable behaviors and you should report any such incidents to your teacher or using report a bully in the school website. Let's make a good and golden choice by making it a nice and wonderful day for one another." This concept should also be addressed by creating posters that should be placed in all classrooms and have teachers discuss them during zero period-which is the first 20-minute period of the school day as previously discussed.

Schools should provide education that is related to bullying and cyber bullying on a newsletter to parents and guardians. Parents should be encouraged to report any suspected bullying to the office or via the school website under the report a bully page. Providing such information to all parents and guardians about school bullying policies is imperative in gaining their support. Such newsletter or pamphlet should also have all the necessary antibullying and cyber bullying policies, and most importantly the interventions that are available when incidents occur. Schools should also through their counselors, communicate with parents or guardians when their children have engaged in serious bullying incidents and such parents should be encouraged to come to the office for a meeting with administration to resolve the issue and find solutions (Bradshaw, 2015; Olweus, 2010; Perlus et al., 2014).

\section{NOTE:}

This article is a summary of the corresponding author Eluojor A. Onnekikami dissertation that was presented as a Partial Fulfillment of the Requirements for the Degree of Doctorate of Psychology to Grand Canyon University, Phoenix Arizona USA.

\section{References}

Albdour, M., \& Krouse, H. (2014). Bullying and victimization among African American adolescents: A literature review. Journal of Child \& Adolescent Psychiatric Nursing, 27(2), 
68-82.

Allen, K. T. (2010). Classroom management, bullying and teach practices. Professional Educator, 34(1), 20-35.

Austin, S. M., Reynolds, G. P., \& Barnes, S.L. (2012). School leadership and counselors working together to address bullying. Education, 133(2), 283-290.

Bhat, C. S. (2008). Cyberbullying: overview ands strategies for school conselors, guidance officers and all school personell. Austrian Journal of Guidence and conselling, 18(1), 53-65.

Bradshaw, C. (2015). Translating research to practice in bullying prevention. American Psychologist, 70(4), 322-332.

Bradshaw, C., Waassdrop, T. E., O’Brennan, L. M., \& Gulemetova, M. (2013). Teachers and education support professionals' perspectives on bullying and prevention: Findings from a national education studies. School Psychology Review, 42(3), 280-297.

Bryce, J., \& Fraser, J. (2013). Its common sense that it's wrong: Young people's Perceptions and Experiences of cyberbullying. Cyberpsychology, behavior, and social networking, 16(11), 783-790.

Bandura, A. (1976). Social learning theory. Englewood Cliffs, NJ: Prentice Hall.

Bandura, A. (1985). Social foundations of though \& action: A social cognitive theory. Englewood Cliffs, NJ: Prentice Hall.

Carter. J., Jernica, M., \& Wilson, F. (2015). Cyberbullying: A $21^{\text {st }}$ century health care phenomenon. Pediatric Nursing, 41(3), 115-125.16(11), 783-790.

Cable News Network. (2011). White house conference tackles bullying. Retrieved from http://whitehouse.blogs.cnn.com/2011/03/10/white-house-conference-tackles-bullying.

Crain, W. (2010). Theories of development: Concepts and applications. Pearsons Publications.

Del Rey, R., Elipe, P., \& Oretga-Ruiz (2012). Bullying and cyber bullying: Overlapping and predictive value of the co-occurrence. Piscothema, 24, 608-613.

Eden, S., Heiman, T., \& Olenik, S. D. (2013). Teachers' perceptions, beliefs and concerns about cyberbullying. British Journal of Education, 44(6), 1036-1052.

Fanti, K.A., \& Georgiou, S.N. (2013). Bullying, victimization, school performance, and mother-child relationship quality: Direct and transactional associations. Journal of Criminology, 5(1), 1-11.

Franks, J., Rawana, E., \& Brownlee, K. (2013). The relationship between strengths in youth and bullying experiences at school. Educational \& Child Psychology, 30(4), 44-58.

Garaigordobil, M., Martinez, V., \& Aliri, J. (2013). Self-esteem, empathy, and aggressive conduct in adolescent victims' of bullying. European Journal of Investigation in Health 
Psychology and Education, 3(1), 29-40

Gofin, R., \& Avitzour, M. (2012). Traditional versus internet bullying in junior high school students. Maternal \& Health Journal, 16(8), 1625-1635.

Hinduja, S., \& Patchin, J. W. (2013). Social influences on cyberbullying behaviors among middle and high school students. Journal of Youth and Adolescence, 42(5), 711-722.

Hinduja, S., \& Patchin, J. W. (2011). High-tech cruelty. Educational Leadership, 68(5), 48-52.

Keith, S., \& Martin. A (2005). Cyberbullying; creating a culture of respect in a cyber world. Reclaminig Children Youth, 13(4), 224-228.

Kiriakidis, P. P., \& Lakes, D. (2013). A case study of Student-to Student Cyber Bullying in one High School. Romanian Journal for Multidimensional Education / Revista Romaneasca pentru Educatie Multidimensionala, 5(2), p101-118.

Kowalski, R., Robin M., Schroeder, A., \& Lattanner, M. (2014). Bullying in the digital age: A critical review and meta-analysis of cyberbullying. Psychological bulletin, 140(4), 1073-1137.

Li, Q. (2009). Cyberbullying in schools: An examination of preservice teachers' perception. Canadian Journal of Learning and Psychology, 34(2). Retrieved from http://www.cjlt.ca/index.php/cjlt/article/viewArticle/494/225.

Li, Q, Smith, P. K., \& Cross D. (2012). Research into cyberbullying: Context. In Q. Li, D. Cross, \& Smith P.K (Eds), Cyberbullying in global playground: Research from international perspectives. Oxford: Blackwell.

National Centre for Education Statistics. (2011). School crime to supplement to the National Crime Victimization Survey: Economics and Statistics Administration. Retrieved from http://nces.ed.gov/programs/crime/pdf/student/SCS09.pdf

Nator, C. E., Padgett, S., \& Roden. (2013). Cyberbullying: A review of the literature. Universal Journal of Educational Research, 1(1), 1-9.

Ockerman, M., Kramer, C., \& Bruno, M. (2014). From the school yard to cyber space: A pilot study of bullying behavior among middle school students. Research in Middle Level Education Online, 37(6), 1-18.

Olweus, D. (2010). Understanding and researching bullying: Some critical issues. In S. R. Jimerson, S. M. Swearer, \& D. L. Espelage (Eds.), Handbook of bullying in schools: An international perspective (pp. 9-34). New York: Routledge.

Perlus, J. G., Brooks, A., Wang, J., \& Iannotti, R. J. (2014). Trends in bullying, physical fighthing, and weapon carrying among $6^{\text {th }}$ to $10^{\text {th }}$ grade students from 1998 to 2010: findings from national studies. America Journal of Public Health, 104(6), 1100-1106.

Robinson, E. (2013). Parental involvement in preventing and responding to cyber bullying, 


\section{Macrothink \\ International Journal of Human Resource Studies \\ ISSN 2162-3058 2017, Vol. 7, No. 3}

Family Matters, 92, 68-76.

Shariff, S. (2008). Cyber-Bullying: Issues and solutions for the school, the classroom and the home. Routledge, New York.

Simplicio, J. (2013). Suck it up, walk it off, be a man: Controversial look at bullying in today's schools. Education, 133(3), 349-349.

Whelan, D. L. (2011). The bully in the backpack. School Library Journal, 57(10), 29-36.

Wheeler, T. (2011). Facebook fatalities: Students social networking, and first amendment. Pace Law Review, 31(1), 182-227.

Whitson, S. (2012). When friendship is used as a weapon: Using life space crisis intervention skills to confront bullying. Reclaiming Children \& Youth, 21(3), 58-61

Whitson, S. (2015). Bringing an end of bullying. Reclaiming Children \& Youth, 24(1), 50-54.

Yin, R. K. (2014). Case study research: Design and methods. $\left(5^{\text {th }}\right.$ ed.). Thousand Oaks, CA: Sage.

Ybarra, M. L., \& Mitchell, K. J. (2004). Youth engaging in online harassment: Associations with caregiver-child relationships, internet use, and personal characteristics. Journal of adolescence, 27(3), 319-336.

\section{Copyright Disclaimer}

Copyright for this article is retained by the author(s), with first publication rights granted to the journal.

This is an open-access article distributed under the terms and conditions of the Creative Commons Attribution license (http://creativecommons.org/licenses/by/4.0/). 